\title{
Hybrid Fuzzy-PID Control in a Thermo Solar Power Plant Condenser
}

\author{
Juan Antonio Romera Cabrerizo \\ Plant Engineer, OPEMASOL \\ Granada, Spain \\ juanantonio487@gmail.com
}

\author{
Matilde Santos, Victoria López \\ Computer Science, Universidad Complutense de Madrid \\ Madrid, Spain \\ msantos@ucm.es, vlopezlo@ucm.es
}

\begin{abstract}
In this paper a predictive hybrid fuzzy-PID control system is designed to be applied in a thermo solar power plant. The intelligent control system keeps the level of the condenser at a desired value. The condenser is a complex element in the plant and the uncertainty that comes from the weather conditions at its inputs makes the control difficult. The dynamic of the system changes continually, depending on the solar resource. The intelligent fuzzy system combined with a conventional one shows good performance, proving that the synergy of these techniques improves the control action.
\end{abstract}

Keywords-fuzzy logic; intelligent control; thermo solar power plant; PID controller; condenser

\section{INTRODUCTION}

On the contrary to other types of power plants, solar plants present a strongly variant working behaviour. The process parameters vary depending on the meteorological conditions. Therefore, this weather dependence has a deep impact on the control systems design.

The main resource of this thermo power plant is the solar one $[1,2]$. The structure of these plants is formed by mirrored cylinder-parabolic collectors (CSP technology) which concentrate sun rays along a pipe situated in the focus of the parabola (Fig. 1). A heat transfer fluid (usually a synthetic oil) which transfers the heat to the steam/water cycle into a train of heat exchangers flows through this pipe. The total group of collectors is called solar field. For more information about this technology, see [3].

The generated steam runs through a classical steam turbine in a modified Rankine cycle, in a similar way to coal, nuclear and natural gas power plants.

In this paper the proposed intelligent system is applied to the condenser, a critical element in the thermo solar power plant, placed downstream of the steam turbine. The inlet steam to the condenser can drastically decrease when a cloud covers the solar field and it can also suddenly increase back as soon as the cloud disappears.

The structure of the paper is as follows. Section 2 is devoted to describe the system that is going to be controlled, the condenser of the thermo solar power plant. The control action, both PID and fuzzy, are presented in Section 3. The design of the fuzzy system is developed in Section 4. Results are discussed in Section 5. The paper ends with the conclusions.

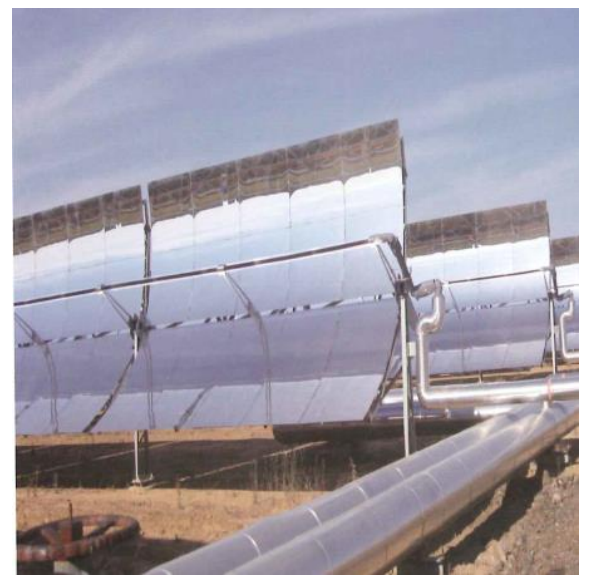

Fig. 1. Cylinder-parabolic collectors in a solar field of a CSP-Thermosolar power plant

\section{DESCRIPTION OF THE SYSTEM TO BE CONTROLLED}

The system to be controlled is a non-linear one, and its dynamics varies depending on the weather conditions. That means that it is a complex system and conventional controllers do not provide a control action good enough. That is why an intelligent hybrid controller based on the combination of fuzzy logic and PID is proposed.

The control is focused on the level of the condenser. In a solar power plant, the condenser generally consists of two parts (Fig. 2):

1. A top body in which the calorific exchange with the cold sink of the cycle takes place. This cold water afterwards is usually pumped into a cooling tower in order to recirculate it again.

2. A bottom body where the condensate of the steam/water cycle is accumulated. This bottom body is called "hot well".

The hot well provides a hydrostatic column to the condensate pump, which returns the liquid water to the cycle. This water is vaporized again to run the turbine and produce electrical power. 


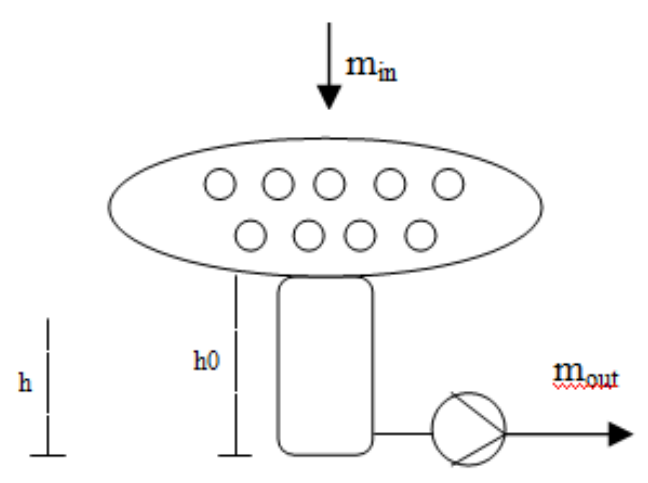

Fig. 2. Typical condenser in steam turbine power plant

\section{A. System Model}

First of all, a model of the system has been obtained in order to simulate it and to test the controllers [4].

The model of the plant is given by the following balance equations:

$$
\mathrm{A} \rho \frac{\mathrm{dh}}{\mathrm{dt}}=\mathrm{m}_{\mathrm{in}}-\mathrm{m}_{\mathrm{out}}
$$

where (see Fig. 2):

h: liquid level in the hot condenser.

A: section of the condenser. It depends on $\mathrm{h}$.

$\rho$ : water density.

$\mathrm{m}_{\mathrm{in}}$ : steam mass flow at the inlet of the condenser.

$\mathrm{m}_{\text {out }}$ : water mass flow pumped out by the condensate pump.

The section of the condenser, A, is not constant and it depends on the level in a non-linear way. It can be expressed as (2),

$$
A=\left(\begin{array}{cc}
A_{0} & \text { if } h<h_{0} \\
2 L \sqrt{2 R h-h^{2}} & \text { if } h>h_{0}
\end{array}\right)
$$

where:

L: length of the upper body of the condenser.

$\mathrm{R}$ : radius of the upper body of the condenser.

$\mathrm{A}_{0}$ : section of the hot well.

Another non-linearity of the system comes from the pump. The pump flow depends on the position of its VFD (Variable Frequency Driver) in a non-linear way (3).

$$
\mathrm{m}_{\text {out }}=\mathrm{f}(\alpha)
$$

Where $\alpha$ is position of the VFD of the pump

The description of this non-linear behaviour can be described by the characteristic curve (Fig. 3). As it is possible to see, the output flow of the pump depends on $\alpha$, the VFD position.

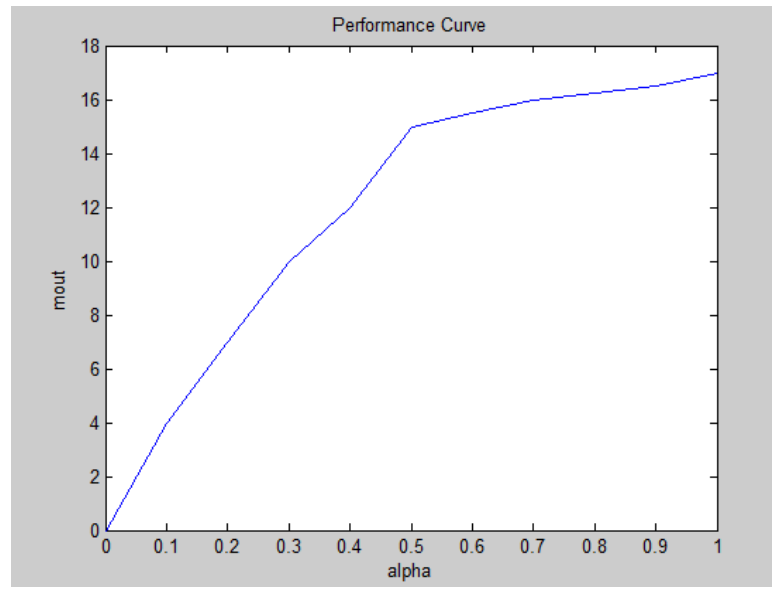

Fig. 3. Characteristic curve of the condensate pump.

Thus, in order to simulate the plant, the inputs are the variables $m_{\text {in }}$ (input flow) and $\alpha$, VFD position, and the output is the variable $h$.

The plant has been simulated by fixing the different constants and parameters as shown in table I:

\section{TABLE I. CONSTANTS AND PARAMETERs OF THE Plant}

\begin{tabular}{lcl}
\hline Constant/Parameter & Value & Units \\
\hline$\rho$ (water density) & 1000 & $\mathrm{~kg} / \mathrm{m}^{3}$ \\
$\mathrm{~A}_{0}$ (section of the hot well) & 0.2 & $\mathrm{~m}^{2}$ \\
$\mathrm{~L}$ (length of the condenser upper body) & 4.75 & $\mathrm{~m}$ \\
$\mathrm{R}$ (radius of the condenser upper body) & 1.4 & $\mathrm{~m}$ \\
$\mathrm{~h}_{0}$ (height of the hot well) & 0.55 & $\mathrm{~m}$ \\
Level set point & 0.50 & $\mathrm{~m}$ \\
$\alpha_{0}$ (initial position of the VFD pump) & 50 & $\%$ \\
ht $=0$ (initial level of the condenser) & 0.50 & $\mathrm{~m}$ \\
$M_{\text {in_max (maximum steam mass flow to the }}$ & 15 & $\mathrm{~kg} / \mathrm{s}$ \\
condenser, base load) & &
\end{tabular}

\section{LEVEL CONTROL STRATEGY}

A good level control in the hot well is crucial in the process. Low levels of water in the condenser could lead to cavitation problems in the pump, and therefore the risk of damaging it. Higher levels could lead to the risk of water returning to the turbine in case of a sudden failure in the vacuum system of the condenser. This could severely damage the machine blades.

Therefore the system is generally controlled by taking the condenser level as the output and the pump VFD as the controlled variable (input). The error is given by the difference between the desired value of the level in the condenser and the actual value of this variable.

\section{A. PID Classic Control}

In order to compare the performance of the proposed intelligent hybrid controller with other controllers, a conventional PID control has been designed [5].

Because of the non-linearities of this system, the PID cannot be applied to the whole operational range. In this case, 
the controller has to be designed for a working point of the system, where a linear approximation can be considered.

But when the process is working far from the point where it has been linearized, it will not work properly and the system will not reach the required specifications. This problem is quite common in the solar power plants, in which the load value (steam mass flow, $\mathrm{m}_{\mathrm{in}}$ ) varies depending on the hardly foreseeable meteorological conditions.

\section{B. Predictive Hybrid Fuzzy-PID Control}

In order to reach the control goal, that is, to maintain the condenser level at a constant desired value, independently of the weather conditions, a hybrid fuzzy-logic controller working with a PID is applied [6], [7], [8].

The fuzzy controller uses the inlet steam mass flow (min) and the level gradient $(\mathrm{dh} / \mathrm{dt})$ as input variables. The output variable is the position value of the VFD pump, $\alpha$.

This output will be directly added to the PID control action, making a predictive correction.

\section{DESIGN OF THE FUZZY CONTROLLER}

The proposed fuzzy control strategy has been implemented by two Fuzzy Controller blocks, each one with an input variable, $\mathrm{m}_{\mathrm{in}}$ and $\mathrm{dh} / \mathrm{dt}$, respectively, and an output variable, correction to the VFD pump position. This correction will be added to the $\alpha$ value calculated by the PID controller.

Each fuzzy system has been developed using the GUI (Graphic User Interface) of the Fuzzy Logic Toolbox of Matlab®. Afterwards, these fuzzy modules have been embedded as a FIS (Fuzzy Inference System).

Both Fuzzy systems are Mamdani type (see [9]). The defuzzyfication method to calculate the crisp value of the fuzzy output is the bisector. The AND connection has been implemented as the minimum, and the OR as the maximum. The aggregation operation is also the maximum.

\section{A. Fuzzy System 1}

The input variable of this system is the derivate of the level of the condenser, that is, dh/dt (level gradient). Three Gaussian membership functions have been assigned to the three fuzzy sets called: decrease, keep constant, increase in the range [-0.1, 0.1] (Fig. 4).

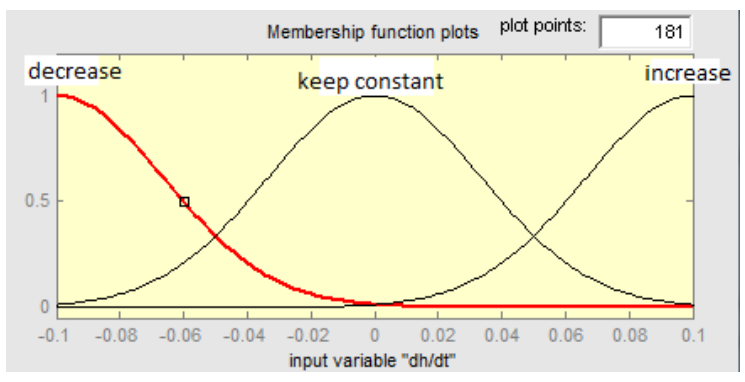

Fig. 4. Fuzzyfication of the input variable dh/dt (level gradient)

The output variable, which is called "alpha1", is defined in the range $[-0.2,0.2]$.
Three linguistic fuzzy variables are assigned: close, maintain, open, described by triangular-shaped membership functions (Fig. 5).

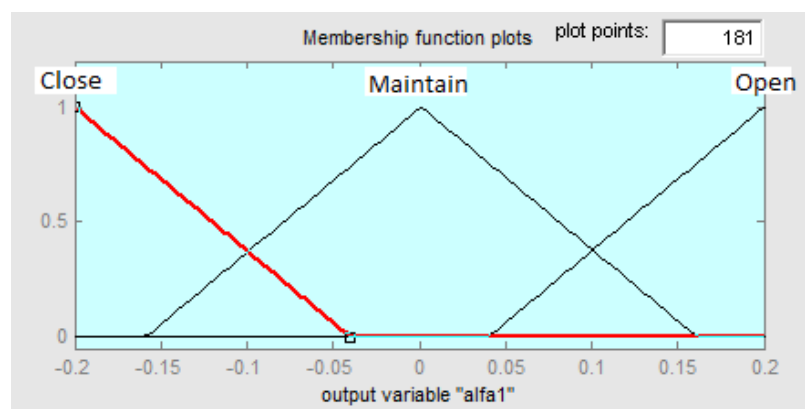

Fig. 5. Membership functions to the output variable (alpha 1)

\section{B. Fuzzy System 2}

The second fuzzy system has been designed in the same way, but now the input variable is the input flow, $\mathrm{m}_{\mathrm{in}}$, and the output the correction to VFD, alpha2.

As it is possible to see in Fig. 6 and Fig. 7, three fuzzy sets have been assigned to each variable. In the case of the input, steam mass flow, they are Gaussian membership functions, labelled as: Low, Medium and High, in an interval between 10 and 20 (Fig. 6).

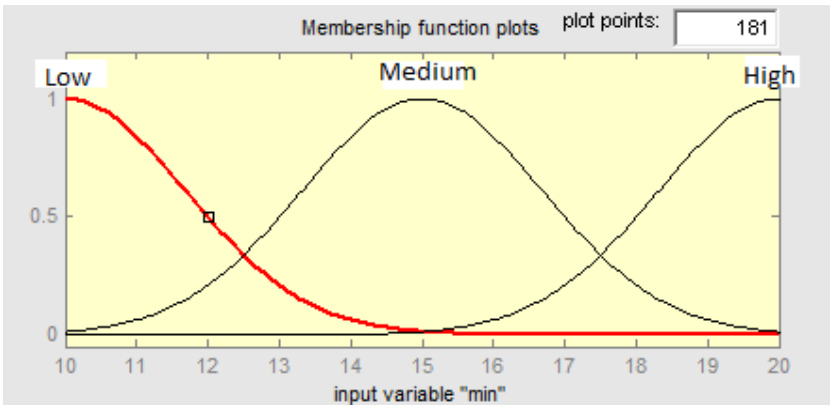

Fig. 6. Fuzzyfication of the input variable $m_{\text {in }}$ (steam mass flow)

Fig. 7 shows the triangular membership functions for the fuzzy sets: close, maintain and open, defined for the output variable.

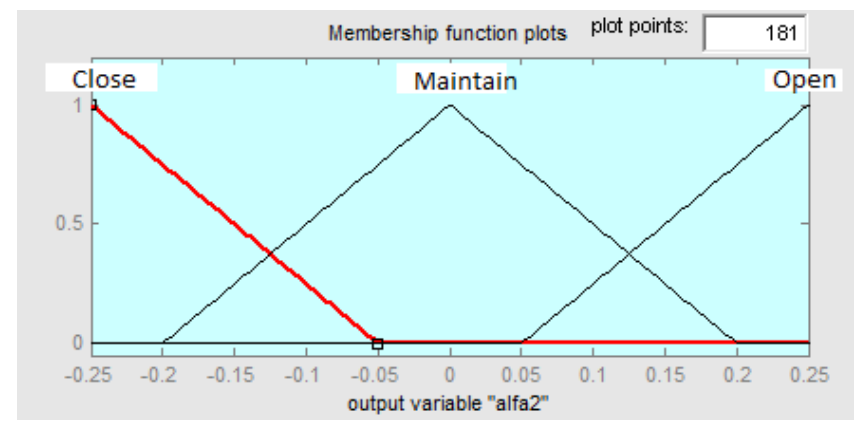

Fig. 7. Membership functions to the output variable (alpha 2) 


\section{Fuzzy Set of Rules}

Once the input and output variables have been described and defined, the set of fuzzy rules is built in linguistics terms. The general rules that describe the behaviour of the system are as follows,

- IF the level increases, THEN open the VFD.

- IF the level keeps constant, THEN maintain the VFD.

- IF the level decreases, THEN close the VFD.

- IF the steam flow is low, THEN close the VFD.

- IF the steam flow is medium, THEN maintain the VFD.

- IF the steam flow is high, THEN open the VFD.

Those rules are afterwards implemented taking into account the variables of the two fuzzy systems that have been previously defined. That is, to achieve "close the VFD", the outputs of the fuzzy systems alpha1 and alpha2 and the control action of the PID, alpha, are added to get the best value.

\section{Simulation Results}

The simulation of the system has been done using the software Matlab®/Simulink. The whole system is shown in Fig. 8 .

As commented in section 2, the main challenge in a thermo solar power plant is to control the system when the load changes due to the changing weather. Therefore, it was decided to use a sine function to simulate the behaviour of the solar input. The valleys correspond to cloudy periods and the peaks to sunny periods. The bias is set to $12 \mathrm{~kg} / \mathrm{s}$ and the amplitude to $3 \mathrm{~kg} / \mathrm{s}$. These parameters allow to simulate a base load $\mathrm{m}_{\mathrm{in}}=15$ $\mathrm{kg} / \mathrm{s}$ (maximum) in sunny periods; in cloudy periods the load falls up to $m_{\text {in }}=9 \mathrm{~kg} / \mathrm{s}$.

With the variation of the load, the level of the condenser varies and the designed control system must be able to face those changes, keeping the level in the condenser constant at a desired value.

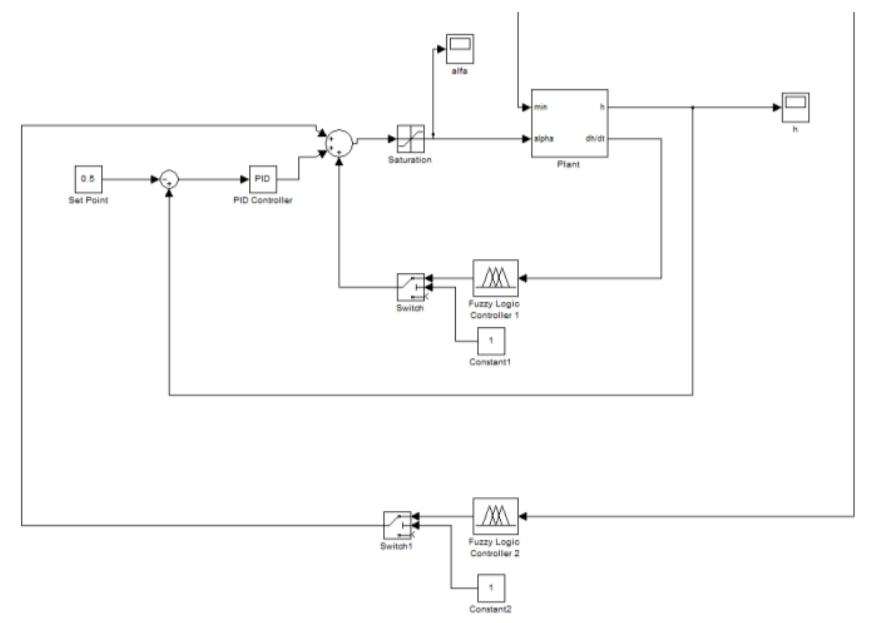

Fig. 8. Simulink diagram of the whole system (plant + control system)

\section{A. PID Results}

First of all, the system is controlled only using the conventional PID controller. For this purpose, the switches of the fuzzy systems (see Fig. 8) are set to zero (deactivated).

The PID parameters are tuned by applying the criteria given in [10]. The obtained values are:

$$
\mathrm{Kp}=25, \mathrm{Ti}=0.2, \mathrm{Td}=0
$$

Therefore, a PI controller is really used. The derivate action amplifies the noise.

The rest of the simulation parameters are the following: integration method ODE-45 (Dormand-Prince [11]), with variable integration step; relative tolerance $10 \mathrm{e}^{-3}$. The simulation time was 20 units.

The results are shown in Fig. 9. From top to bottom, Level in the condenser $(h)$, position of $\operatorname{VFD}(\alpha)$, and steam mass flow to the condenser $\left(\mathrm{m}_{\mathrm{in}}\right)$
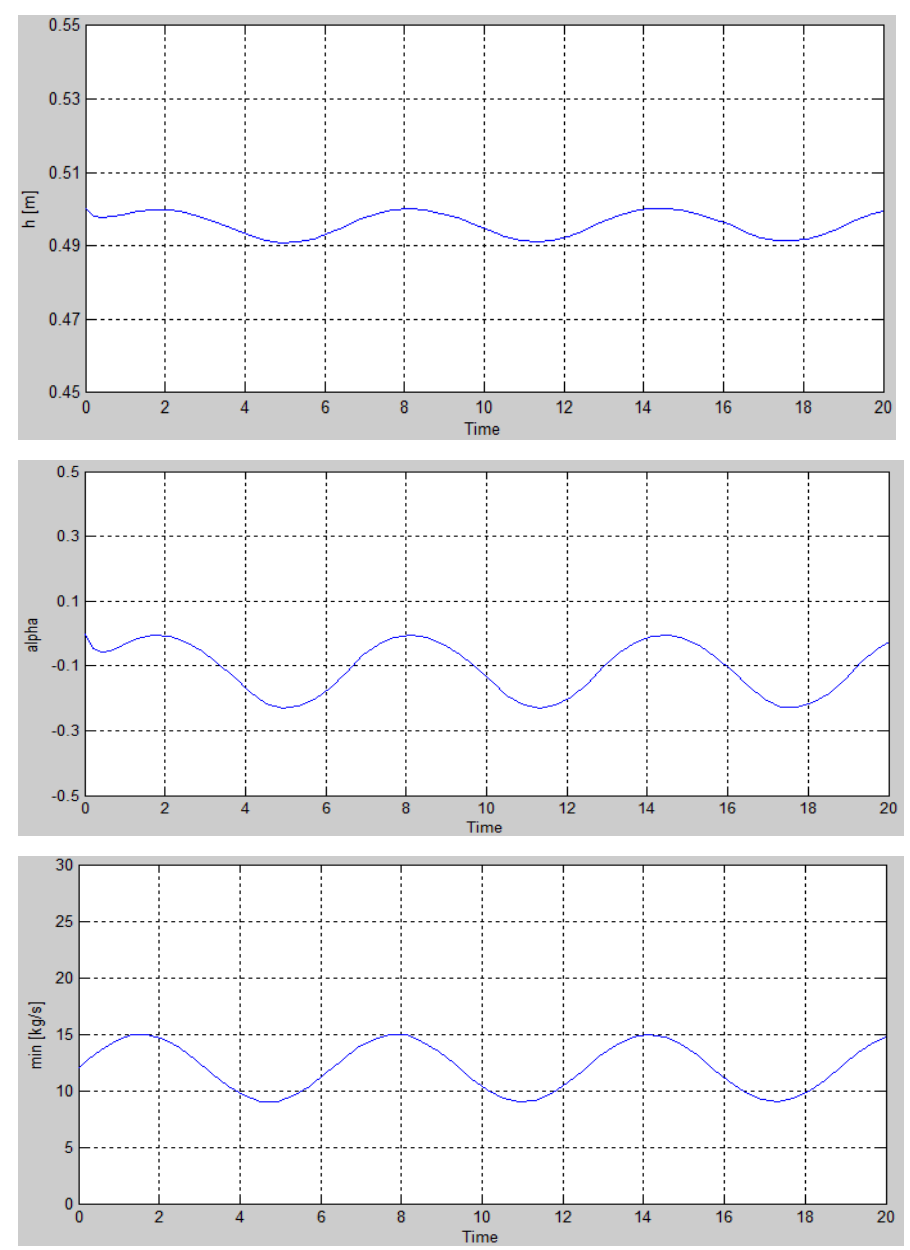

Fig. 9. PID control. From top to botto: Level in the condenser (h), position of $\operatorname{VFD}(\alpha)$ and steam mass flow to the condenser $\left(\mathrm{m}_{\mathrm{in}}\right)$

It can be observed that the PID controller does not achieve a constant level of the condenser. In fact, the level drops below the set point $(4 \%)$. The position of the VFD (middle graph) has a similar behaviour. 


\section{B. Hybrid Fuzzy-PID Results}

Now, the fuzzy systems are connected, setting to 1 the corresponding switches (see Fig. 8). The simulation runs with the same parameters as the previous one.

Fig. 10 shows how although the input, steam mass flow, is a sine function, the hybrid fuzzy-PID system allows the condenser to keep the level constant, achieving the control goal. The error is smaller than $0.2 \%$, which is acceptable.
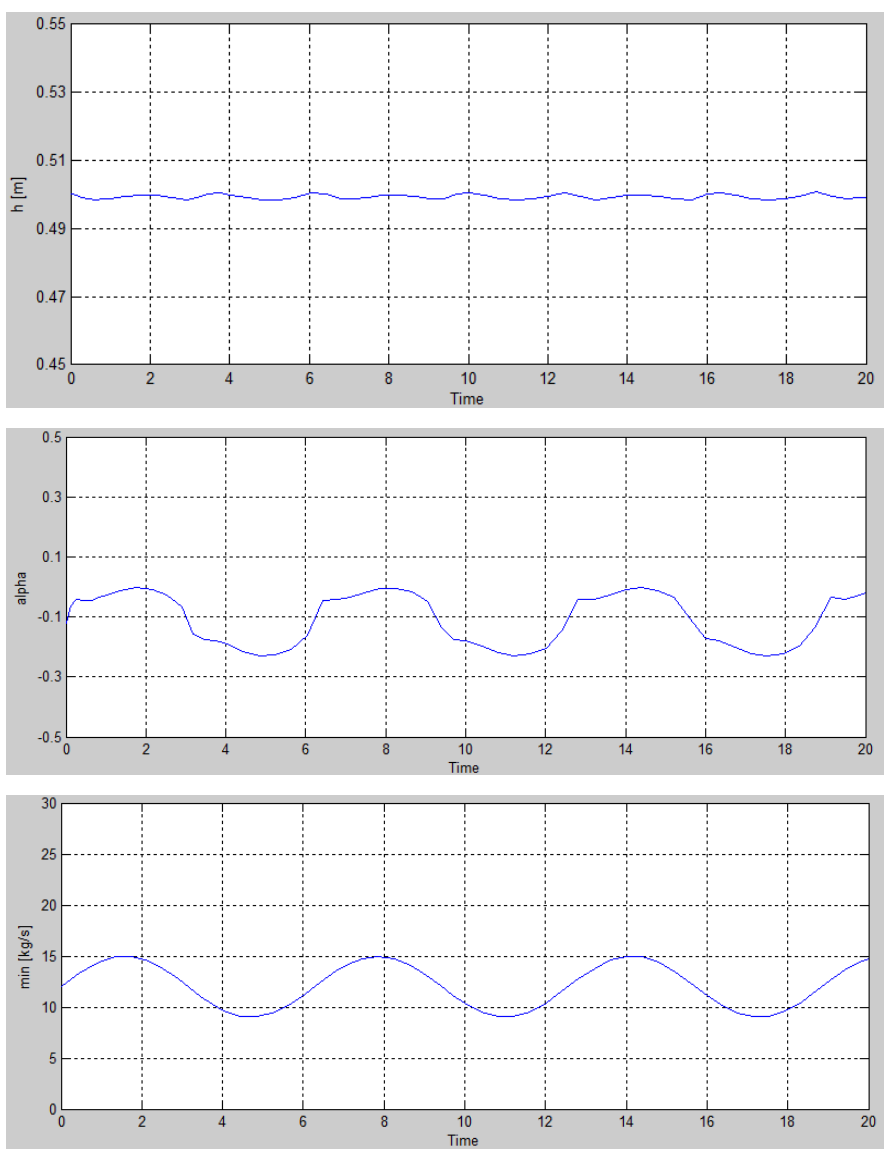

Fig. 10. Hybrid Fuzzy-PID control. From top to bottom: Level in the condenser (h), position of VFD $(\alpha)$ and steam mass flow to the condenser $\left(\mathrm{m}_{\text {in }}\right)$.

This is achieved thanks to the predictive character of the proposed fuzzy design. The abrupt changes in the control action (position of the VFD pump) that can be seen in the middle graph of Fig. 10 are due to the continuous correctionprediction of the fuzzy systems.

\section{CONCLUSIONS}

It has been proved the improvement obtained when using fuzzy logic to deal with real systems that present non-linearities (in this case, geometry of the condenser and characteristic curve of the condensate pump), and uncertainty that comes from the input (solar resource). These two issues make the system complex.

Under these changing conditions, the linear mathematical model of the plant in which the PID design is based does not work for all the operational range of the plant.

Besides, the linguistic fuzzy rules that implement the hybrid system are intuitive and close to the natural language of an expert control operator and therefore can be implemented in an easier way.

Future works include the comparison and improvement of this intelligent controller approach with others more advanced techniques (optimization and fine tuning by genetic algorithms, neural networks, and evolutive expert systems).

\section{ACKNOWLEDGMENT}

Authors appreciate the helpful comments of the reviewers.

\section{REFERENCES}

[1] M. Mikati, M. Santos, and C. Armenta. Electric grid dependence on the configuration of a small-scale wind and solar power hybrid system. Renewable Energy, 57, 587-593, 2013

[2] M. Mikati, M. Santos, and C. Armenta. Modeling and Simulation of a Hybrid Wind and Solar Power System for the Analysis of Electricity Grid Dependency. Revista Iberoamericana de Automática e Informática Industrial, vol. 9, no. 3, 267-281, 2012

[3] H. Price, E. Lupfert, D. Kearney, E. Zarza, G. Cohen, R. Mahoney, and R. Gee. Advances in parabolic trough solar power technology. Journal of solar energy engineering, 124(2), 109-125, 2002.

[4] A.M. Patnode. Simulation and performance evaluation of parabolic trough solar power plants (Doctoral dissertation, University of Wisconsin), 2006.

[5] Z. Ye, W.J. Cai, and C.C. Hang. PID control for multivariable processes (Vol. 373). Berlin: Springer, 2008.

[6] I. Erenoglu and I. Eksin. An intelligent hybrid fuzzy PID controller. In European Conference on Modelling and Simulation 2006, pp. 62-67.

[7] W. Li. Design of a hybrid fuzzy logic proportional plus conventional integral-derivative controller. Fuzzy Systems, IEEE Transactions on, 1998, 6, 4, pp. 449-463.

[8] Z. Kovacic and S. Bogdan. Fuzzy controller design: theory and applications. CRC press, 2005.

[9] E.H. Mamdani,. Application of fuzzy algorithms for control of simple dynamic plant. Proceedings of the Institution of Electrical Engineers. Vol. 121. No. 12. IET Digital Library, 1974.

[10] K. Åström and T. Hägglund. Advanced PID control. ISA-The Instrumentation, Systems, and Automation Society; Research Triangle Park, NC 27709, 2006.

[11] J.R. Dormand and P.J. Prince. A family of embedded Runge-Kutta formulae. Journal of computational and applied mathematics, 6(1), 1926, 1980. 